\title{
The international arena of medical physics: where is Australasia?
}

\author{
Natalka Suchowerska
}

Published online: 29 June 2010

(C) Australasian College of Physical Scientists and Engineers in Medicine 2010

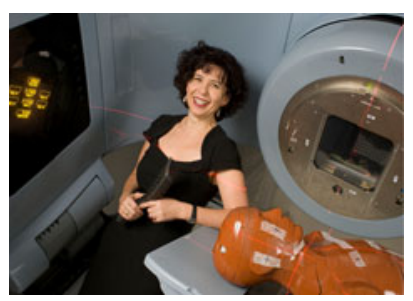

Medical physics has made significant scientific progress in the last decade. The results have influenced the way we practice medicine. The role of technology and the supporting physics and engineering in health care has never been greater. Consequently, medical physics research has become more complex and work is often done by only a few highly recognized groups of scientists or institutions around the world. These developments are widening the gap between research conducted in highly developed countries and the rest. But even more significant is the gap in clinical practice. Developing countries often lack equipment or trained personnel to fully utilize existing equipment. Shortages of qualified staff and equipment are growing constraints to treating cancer effectively. Many experts predict a long-term crisis in cancer management, not only in the availability of treatment options but also in assuring patients' safety. Adapted from an abstract submitted to AAPM (2010) by Harald Paganetti, Chairman IOMP Science Committee.

N. Suchowerska $(\bowtie)$

Royal Prince Alfred Hospital, Camperdown, NSW 2050, Australia

e-mail: natalka@email.cs.nsw.gov.au
Australia's population will reach 22.5 million some time this year, ranking it 51st in the world [1]. New Zealand's population is approximately a fifth of this, ranking it 123rd in the world. Combined, the peoples of Australasia represent $0.394 \%$ of the world population. It seems almost ludicrous to expect some sort of unique contribution from antipodean medical physicists to the world of medicine and health care and yet I believe that we contribute significantly above expectation for a population of this ranking.

If we look at the world of health care, Australia finds itself in a very unusual place i.e. half way between having a national health care system and a totally private health care system. The situation in New Zealand is similar. Foreigners find this system more difficult to understand than Australian Rules Football or even cricket. The consequences of such a dichotomy in health services are many, but in the fields where medical physicist predominantly work, this means that we in Australasia have access to technology and equipment equal to the most affluent countries with private health systems, while still retaining the principles of a national health system. For example although in our department we have five linear accelerators with current cutting edge technology, outpatients are bulk billed to Medicare.

Health systems which are based on financial returns i.e. profits, pose a problem. As a Conference Visitor recently put it, financial returns on investments in health care are highly motivated in keeping the patient alive, but not cured. Only with this scenario can profits be maximised. If the patient is cured or is permitted to die, they are no longer in need of expensive drugs or treatment technologies. Conversely it can be said that a cured patient is no longer a burden on overstretched health resources.

In the light of increasing costs of technology to support modern medical practices, it is hardly surprising that the 
health outcomes are prime motivators for those who do not need to profit financially from health services. Although any medical physicist would be keen to take out the latest medical equivalent of a red Ferrari, an ever present awareness of the necessity to balance the patient benefits against the costs in health care leads us to making judgements about novel medical gadgets, which are not always in keeping with the rest of the world. We judge the situation on its merits and match the device to the need. It is hardly surprising then that Prof Barry Allen as president of IOMP convened a Health Technology and Training Task Group (23 July 2007) to identify key technical needs in health services for a specific regional location. It is envisioned that recommendations for appropriate equipment and training to satisfy the specific local needs, can then be made.

Specific local health care needs must take into consideration the available infrastructure, including trained specialists to realise the full potential of the technology. Many owners of a 4 wheel drive, cruise about town, never getting their tyres muddied, which is a waste of technical potential. In a similar way each item of sophisticated medical technology must have the people who know how to drive it, how to manoeuvre it safely, how to care for it and how to make use of it to its full potential. The approaches to education and training of medical physicists in Australia and New Zealand have seen a metamorphosis over the past decade. This development has had a far reaching international influence. The IAEA project to develop Clinical Training Guidelines (project RAS6038) had a dominant Australian influence, tapping into the locally grown expertise. Now this documentation [2] has been used in several countries of Asia (Thailand, Philippines, India, etc.). Thailand has just graduated its first candidates through the new radiation oncology structured training program (Bangkok and Chiang Mai) [3].

Clearly, having taken the journey of rethinking and reinventing Australasian education of specialists, our medical physicists have created ripples that have influenced international approaches.

One of the unwanted results of being the 'clever country', is that an 'export' in experts is created. The majority of our Australasian 'exports' have gone on to become world leaders in their area of medical physics expertise. The Canadians claim Dr Wayne Beckham, Medical Physics Leader to the Province of British Columbia. The United States have Dr Paul Keall, Director of the Radiation Physics Division at Stanford University and others have adopted Rhonda Brown, Alun Beddoe, Peter Hoban, John le Heron, Sergei Zavgorodni, Mostafa Heydarian, Chris Amies, Dave Murray, Don McLean ...this is but a few of the medical physicists of my generation, but the list seems endless as we look further or cross over into the other specialist areas of medical physics and biomedical engineering. All of these exports gained their foundations and the framework of their thinking in Australasia.

Although a generalisation, the striking feature about the majority of Australasian medical physics 'exports' is their capacity for innovation, to think outside the square and avoid the constraints of existing dogma. It will not surprise those who have scanned the Olympic medal tally that larger countries tend to win more medals. The obvious exception, especially in 2008, was Australia, who won the sixth largest number of medals [4].

Without wanting to reiterate the stereotypes associated with the ANZAC spirit, Australasians are characterised by being goal driven, focussed and unafraid of the hard yards, but enjoying a cold beer at the end. With a population of just over 22 million, Australia is also one of the leading Nobel Prize-winning countries in per capita terms. It is difficult to determine exactly how many Nobel laureates Australia has produced. There are at least 10 laureates who are generally regarded as being 'Australian' [5]. Of the 10 Nobel Prizes generally accepted as having been awarded to Australians since 1915, nine were for science or medicine and one was for literature. Another eight people with links to Australia have won Nobel Prizes, most of them for science or medicine.

There are many Australasian inventions, which have not won prestigious prizes but have had equally far reaching influence on peoples' lives. Consider the Hills hoist, the black box flight recorder, the wine cask and the Victa lawn mower. For years as an English migrant to these shores I thought of it as a Victor lawn mower, but no, this is not the flavour of Australian innovations. They do not look for Victory but for job well done and time to relax and reflect, with consideration of possible improvements. Our good ideas come in simple packaging with acronyms with as much sex appeal as a Tooheys (beer) or a lamington. How can we be surprised, when we are goal driven, focussed and unafraid of hard work?

Having said all this we then return to the question, what can the medical physicists from the antipodeans uniquely bring to the world of medicine and health care?

Evidence for the impact of our ideas and value of our human resources in the international arena are many. One of these is the ACPSEM for PNG National Radiotherapy Treatment Centre appeal. The significant driving force behind this campaign has been medical physics registrars, individuals still in training. Although the work on the ground is done by dedicated qualified volunteers, much of the fund raising and advocacy is done by junior medical physicists. This includes the fun-run to be held this month in Melbourne. In the PNG project, there will be no big shiny state of the art medical devices that make a nice 
ping at the right time. There will be no big medical device patents and corporate windfalls. No great awards or pageantry are expected. But for those that choose to make a difference, there is certainty that the rewards will be great, because someone, somewhere will be given hope.

I believe the CanMEDs [6] scoping of a professional medical practitioner applies equally to the medical physicist. A medical physicist should be: a professional, a communicator, a scholar, a collaborator, an advocate and a manager [5]. The situation governs which facet needs to be called upon. Competence in each facet is needed, although the individual may not be equally strong in all. The Medical Physics profession is strengthened by its diversity. Clearly if the infrastructure in Australasia could support this diversity, we would go a long way to stemming the 'export' problem, which diminishes us locally. Ideas can be shared, but not people. In not utilising the full potential of our diversity, we may be keeping the mud off our tyres, but are we maximising the potential of our human resources?

\section{References}

1. Wikipedia, the free encyclopedia. List of Countries by population. http://en.wikipedia.org/wiki/List_of_countries_by_population

2. Clinical training of medical physicists specialising in radiation oncology (2009) IAEA Training Course Series 37, Vienna. ISSN 1018-5518

3. Duggan L (2010) ACPSEM TEAP NSW Clinical Program Coordinator, Personal communication

4. Olympic Glory in proportion, website listing Olympic medal tally. http://www.medalspercapita.com/about.html

5. Australian Government Department of Foreign Affairs and Trade website. http://www.dfat.gov.au/facts/nobel_prize_winners.html

6. CanMEDS, Royal College of Physicians and Surgeons of Canada, Faculty of Medicine, University of Toronto. http://www.dept medicine.utoronto.ca/CanMEDS.htm 